\title{
EFEKTIVITAS COGNITIVE BEHAVIOR THERAPY (CBT) UNTUK MENINGKATKAN KUALITAS TIDUR PENDERITA GEJALA INSOMNIA USIA DEWASA AWAL
}

\author{
Artani Hapsari $^{\left.1^{*}\right)}$, Afif Kurniawan ${ }^{1}$ \\ ${ }^{1}$ Departemen Psikologi Klinis dan Kesehatan Mental, Fakultas Psikologi, Universitas Airlangga, \\ Surabaya 60286, Indonesia \\ ${ }^{*}$ E-mail: artanihapsari@gmail.com
}

\begin{abstract}
Abstrak
Dewasa awal merupakan masa perkembangan kognitif dan fisik yang berfungsi secara optimal sehingga memiliki aktivitas dan pengalaman baru yang rentan pada gaya hidup yang kurang sehat, seperti merokok, konsumsi alkohol, dan konsumsi kafein berlebihan. Semakin banyak aktivitas, individu dewasa awal dapat menjadi tertekan sehingga berdampak pada pola tidur yang tidak teratur, kualitas tidur menurun, dan mengalami gejala insomnia. Tujuan dari penelitian ini adalah menguji efektivitias Cognitive Behavior Therapy (CBT) untuk meningkatkan kualitas tidur pada penderita gejala insomnia usia dewasa awal. Penelitian ini menggunakan metode penelitian eksperimental dengan desain eksperimen one group pre-test post-test dan mengambil contoh 4 subjek dengan rentang usia antara 20-25 tahun. Pittsburgh Sleep Quality Index (PSQI) digunakan sebagai skala pengukuran dan kemudian dianalisis menggunakan teknik statistik Wilcoxon Signed-Rank Test. Hasil menunjukkan adanya perbedaan signifikan terhadap kualitas tidur keempat subjek sebelum dan sesudah dilakukan intervensi CBT. Komponen stimulus control, sleep restriction, sleep hygiene education, dan cognitive therapy adalah komponen yang berpengaruh pada perubahan kualitas tidur subjek. Selain itu, faktor internal seperti motivasi dan kepatuhan subjek dalam menjalani terapi serta faktor eksternal seperti dukungan dari sesama subjek atau keluarga juga menjadi faktor yang memengaruhi perubahan kondisi subjek penelitian.
\end{abstract}

Kata Kunci: cognitive Behavior Therapy, dewasa awal, gangguan tidur, insomnia, kualitas tidur

\section{Effectiveness of Cognitive Behavioral Therapy to Increase Sleep Quality in Young Adults Insomnia Patients}

\begin{abstract}
Early adulthood becomes a period which cognitive and physical development functions optimally so that it affect young adult to have new activities and experiences that are vulnerable to an unhealthy lifestyle, such as smoking, alcohol consumption, and excessive caffeine consumption. The more daily activity they have, the higher they become depressed that impacts on irregular sleep patterns, decreased sleep quality, and experience symptoms of insomnia. The purpose of this study was to examine the effectiveness of Cognitive Behavior Therapy (CBT) to improve sleep quality in patients with insomnia symptoms in early adulthood. The study used an experimental research method with one group pre-test post-test experimental design, and took samples of 4 people with age range between 20-25 years. The Pittsburgh Sleep Quality Index (PSQI) was used as measurement tool and furthermore writer used Wilcoxon Signed-Rank Test to analyze the data. The results showed a significant sleep quality difference of 4 subjects prior and after CBT. CBT's components such as stimulus control, sleep restriction, sleep hygiene education, and cognitive therapy believed to affects sleep quality in this study. Other than that, internal factors like motivation and obedient towards therapy and also external factors like support from fellow subjects or family members become factors which affects changes in subjects' condition.
\end{abstract}

Keywords: cognitive behavior therapy, insomnia, sleep disorder, sleep quality, young adults

\section{PENDAHULUAN}

Setiap individu akan terus berkembang dan memiliki tugas perkembangan yang harus dicapai. Dewasa awal menurut Santrock (2011) berusia 18-25 tahun yang mengalami masa peralihan dari masa remaja ke masa dewasa. Tugas perkembangan dari dewasa awal adalah melakukan penyesuaian diri dari transisi masa remaja ke masa dewasa, menyelesaikan pendidikan, mulai bertanggung jawab untuk mencukupi kebutuhan secara mandiri, mencari pekerjaan dan nafkah, mencari pasangan hidup, dan membangun keluarga baru (Hurlock, 2011). Setiap tahapan perkembangan pasti memiliki masa kritisnya, begitu pula dengan masa dewasa awal. Dewasa awal memiliki kognitif dan fisik yang 
berfungsi secara optimal serta dituntut untuk belajar menjadi individu dewasa dari segi perilaku, pemikiran, dan tanggung jawab sehingga membutuhkan penyesuaian tugastugas orang dewasa (Feldman, 2018).

Tahun-tahun awal masa dewasa, individu menghadapi krisis yang disebut dengan quarterlife crisis yang dihadapkan dengan kesulitan menyelesaikan pendidikan, mencari lapangan pekerjaan, memulai hidup mandiri, menghadapi perpisahan dalam hubungan percintaan, dan berulang kali memulai kembali kegagalan yang dialami (Robinson \& Wright, 2013). Hasil penelitian Chamberlain dan Grant (2019) menyatakan bahwa masa dewasa awal merupakan proses transisi pada individu untuk tidak lagi bergantung pada keluarga, seperti: mulai belajar kehidupan di universitas, menjadi karyawan tetap untuk pertama kali, dan membangun hubungan sosial jangka panjang. Lee et al. (2015) menemukan bahwa menjadi pengangguran pada usia dewasa awal berhubungan dengan meningkatnya perilaku konsumsi alkohol, merokok, dan menghisap ganja karena memiliki pekerjaan adalah salah satu identitas yang dapat meningkatkan harga diri pada individu. Penelitian yang dilakukan oleh Liu, Modrek, dan Sieverding (2017) menyatakan bahwa faktor lingkungan dan psikologis individu dewasa awal dapat memengaruhi arah perkembangan individu dewasa awal melalui transisi menuju kedewasaan dan mengatasi penyebab stresseperti manajemen diri dan waktu, lebih siap menghadapi kegagalan, dan dapat melakukan interaksi sosial dengan baik.

Penelitian yang dilakukan oleh Sarmento (2015) menyatakan adanya tren peningkatan masalah kesehatan mental pada mahasiswa di Eropa yang dituntut untuk secara mandiri mengatur kehidupannya, termasuk kesehatan, pendidikan, dan juga karir di masa depan. Beberapa dewasa muda yang kurang memiliki keterampilan sosial yang baik akan merasakan tekanan sehingga berdampak pada kesehatan mental seperti depresi, kecemasan, serta penyalahgunaan obat dan alkohol. Selain itu, dalam upaya memenuhi tugas perkembangannya, individu dewasa awal juga dipengaruhi oleh lingkungan eksternal yang dengan mudah memberikan penilaian atau tolak ukur usia terhadap perilaku (contoh: harus bekerja sebelum usia 25 tahun) yang berakibat pada munculnya ekspektasi atau harapan terhadap diri individu dewasa awal. Apabila tidak dapat memenuhi ekspektasi tersebut, akan muncul perasaan tidak berdaya, frustasi, dan tekanan yang dapat meningkatkan risiko permasalahan kesehatan mental pada individu dewasa awal (Chan, Moore, Derenne \& Fuchs, 2019).

Berdasarkan data WHO (2016), terdapat sekitar 35 juta orang mengalami depresi, 60 juta orang mengalami gangguan kecemasan, dan lebih dari 100 juta orang mengalami stres berat. Hasil lain yang dilakukan oleh American Psychologycal Association (APA) (2017) pada warga Amerika menunjukkan bahwa sebanyak 59,0 persen dari kelompok usia 18-38 tahun mengalami stres. Sementara di Indonesia memperlihatkan bahwa jumlah kasus gangguan jiwa terus meningkat setiap tahunnya. Berdasarkan penelitian Aulia dan Panjaitan (2019) ditemukan bahwa dari 108 orang subjek mahasiswa tingkat akhir, sebanyak 47,2 persen memiliki tingkat kesejahteraan psikologis yang rendah yang diakibatkan oleh buruknya regulasi waktu, kurangnya dukungan, dan buruknya kualitas tidur karena stres dan tekanan yang dialami.

Munculnya gangguan psikologis ini dapat meningkatkan risiko individu mengalami gangguan tidur atau sebaliknya gangguan tidur dapat pula meningkatkan risiko individu mengalami gangguan psikologis dan emosi. Kedua gangguan ini saling berkaitan dan dapat menyebabkan gangguan utama atau gangguan penyerta (Williams, Roth, Vatthauer, \& McCrae, 2013). Gejala gangguan psikologis seperti stres, depresi, kecemasan, dan PTSD (Post Traumatic Stress Disorder) dapat menyebabkan individu sulit tidur, sulit menjaga ritme tidur, memiliki kualitas tidur yang buruk, mimpi buruk, dan mengantuk sepanjang hari (Hombali et al., 2018). Sebanyak 90,0 persen pasien depresi dilaporkan mengalami insomnia, pasien bipolar mengalami hipersomnia (23,0\%-78,0\%), dan pasien GAD (Generalized Anxiety Disorder) (60,0\%-70,0\%) dan gangguan panik mengalami insomnia kronis (Hombali et al., 2018; Ypsilanti, Lazuras, Robson, \& Akram, 2018). Gangguan tidur tersebut dapat membawa dampak negatif pada upaya pengobatan dan penanganan terhadap gangguan psikologis dan meningkatkan risiko kekambuhan serta memperparah gangguan mental lainnya yang diderita (Cunnington, Junge \& Fernando, 2013).

Insomnia adalah salah satu gangguan tidur yang paling umum dialami oleh individu. Data populasi dunia berdasarkan DSM-5 (2013) menunjukkan sepertiga dari individu usia dewasa menunjukkan gejala insomnia, mengalami hambatan terkait dengan aktivitas sehari-hari $(10,0 \%-15,0 \%)$, dan mengalami 
gejala-gejala lain yang memenuhi kriteria gangguan insomnia (6,0\%-10,0\%). Kasus insomnia juga dialami oleh sebagian populasi penduduk di Indonesia, terutama usia dewasa awal. Sebuah studi yang dilakukan pada salah satu perguruan tinggi di Indonesia menyatakan bahwa sebanyak 45,7 persen dari total 70 responden mahasiswa usia 16-20 tahun mengalami insomnia (Gunanthi \& Diniari, 2016). Masa studi dan beban studi berpengaruh pada risiko mahasiswa mengalami insomnia karena kadar stres yang lebih tinggi dan juga beban tanggung jawab yang lebih berat (Giri, Baviskar, \& Phalke, 2013).

Penelitian yang dilakukan oleh Taylor et al. (2011) menyatakan bahwa dewasa awal yang menjalankan perannya sebagai mahasiswa memiliki risiko besar mengalami penurunan kesehatan mental akibat stres yang dialami karena adanya tekanan akademik dan permasalahan pribadi lainnya. Pola hidup ini akan berpengaruh pada kinerja organ tubuh sehingga meningkatkan risiko insomnia. Sejalan dengan penelitian Taylor et al. (2011); Nurdin, Arsin dan Thaha (2018) juga menyatakan bahwa insomnia banyak dialami oleh individu pada masa produktif (18-30 tahun) karena pada kelompok usia ini kemampuan individu untuk pemecahan masalah semakin kompleks dan cukup beresiko terhadap peningkatan stress. Penurunan kualitas hidup dan insomnia pada usia produktif juga dapat dikaitkan dengan perasaan cemas, rasa sedih, tekanan, dan emosi negatif lainnya yang disebabkan oleh peristiwa di masa lalu, beratnya beban hidup, dan pola perilaku coping yang kurang tepat (Liu, Modrek \& Sieverding, 2017).

Insomnia adalah gangguan kesulitan untuk tidur, kesulitan menjaga pola tidur, atau memiliki kualitas tidur yang buruk meskipun memiliki cukup kesempatan untuk tidur (Walia \& Mehra, 2016). Insomnia akut biasanya terjadi kurang dari 4 minggu dan dapat dikaitkan dengan penyebab yang spesifik, sedangkan insomnia kronis terjadi kurang lebih selama 6 bulan dan tidak mudah ditemukan penyebabnya (Williams, Roth, Vatthauer, \& McCrae, 2013). Insomnia dapat menyebabkan munculnya berbagai penyakit baru seperti meningkatkan risiko kecelakaan karena mengantuk saat berkendara, meningkatkan risiko terserang penyakit kronis dan obesitas, dan juga menyebabkan depresi (Walia \& Mehra, 2016). Insomnia dapat didefinisikan secara primer dan sekunder, apabila gejala insomnia berkaitan dengan kondisi fisik atau psikologis lain maka kondisi tersebut adalah diagnosis primer dan insomnia merupakan diagnosis sekunder (National Institute of Health, 2005).

Penanganan insomnia berfokus pada diagnosis utama dengan asumsi bahwa kesembuhan diagnosis utama juga akan memengaruhi kesembuhan dari insomnia sebagai diagnosis sekunder. Istilah sekunder kemudian berganti menjadi comorbid karena ketika insomnia terjadi bersamaan dengan kondisi lain akan sulit mengidentifikasi kondisi mana yang menyebabkan satu dan lainnya (Williams, Roth, Vatthauer, \& McCrae, 2013). Morawetz (2003) menyatakan bahwa ketika pasien depresi dengan keluhan insomnia ditangani untuk memperoleh kualitas tidur yang lebih baik akan menghasilkan kualitas tidur yang optimal bahkan sebanyak 70,0 persen pasien dengan keluhan tersebut juga mengalami penurunan gejala depresi. Pernyataan ini juga diperkuat dari hasil penelitian yang dilakukan oleh Manber et al. (2011) bahwa pasien depresi yang mendapatkan terapi untuk mengurangi gejala insomnia menunjukkan peningkatan energi, produktivitas, self-esteem, dan peningkatan aspek well-being lainnya tanpa munculnya gejala depresi yang semakin parah. Pasien yang awalnya terpikir untuk bunuh diri semakin membaik kondisinya karena mengalami peningkatan kesejahteraan dalam dirinya.

Beberapa faktor yang menyebabkan insomnia, salah satunya dijelaskan oleh teori etiologi dari Spielman yaitu 3-P Model of Insomnia. Teori ini menjelaskan bahwa insomnia disebabkan oleh tiga faktor, yaitu predisposing conditions (kondisi yang melekat pada diri individu seperti jenis kelamin, usia, genetik, gaya hidup, kondisi kesehatan fisik dan mental), precipitating circumstances (kejadian pencetus yang biasanya bersifat traumatis), dan perpetuating factors (pergeseran pola kognitif dan perilaku yang memperparah kondisi insomnia) (Williams, Roth, Vatthauer \& McCrae, 2013). Penelitian dan penanganan yang dilakukan biasanya berfokus pada tiga jenis perpetuating factors, yaitu aktivitas nontidur yang dilakukan di dalam kamar tidur, kecenderungan untuk tetap berada di atas tempat tidur saat bangun, dan kecenderungan untuk menghabiskan waktu secara berlebihan di atas tempat tidur. Kebanyakan aktivitas tersebut diasosiasikan dengan hal-hal negatif dari predisposing dan precipitating sehingga kondisi insomnia semakin parah (Kryger, Roth \& Dement, 2017). Insomnia apabila tidak segera ditangani akan menyebabkan 
munculnya dampak-dampak negatif dalam jangka pendek maupun jangka panjang. Menurut Driver et al. (2012), dampak jangka pendek insomnia adalah individu yang telah merasa stres akan meningkat kadarnya, mengalami kesulitan konsentrasi, dan merasa lelah sepanjang hari sehingga berakibat pada kinerja otak. Sementara efek jangka panjang individu yang stres bisa menjadi depresi akut, meningkatkan risiko penyakit jantung, dan meningkatkan risiko diabetes.

Beberapa cara yang dapat dilakukan untuk mengatasi gangguan tidur yaitu dengan terapi obat maupun non obat (Cunnington, Junge, \& Fernando, 2013). Salah satu metode nonfarmakologi yang efektif untuk mengurangi gejala gangguan tidur adalah Cognitive Behavior Therapy (CBT) yang tahapantahapannya khusus disusun untuk kasus insomnia (Taylor \& Pruiksma, 2014). CBT adalah metode terapi yang dikembangkan oleh Aaron Beck yang bertujuan untuk mengubah distorsi kognitif untuk menghasilkan satu perilaku baru yang lebih adaptif (McMain, Newman, Segal \& DeRubeis, 2015). CBT dianggap efektif menangani insomnia karena dalam intervensinya CBT merupakan gabungan dari terapi secara kognitif dan perilaku yang mana penanganan insomnia kronis memerlukan intervensi secara langsung untuk memperbaiki perilaku, pola pikir yang salah, dan hubungan antarkeduanya yang memperparah kondisi penderita (Cunnington, Junge, \& Fernando, 2013). Selain itu, komponen CBT untuk insomnia juga didesain sesuai dengan teori etiologi the Behavioral Models of Insomnia yang dikemukakan oleh Spielman sehingga implementasinya menekankan pada adanya perubahan kognitif dan perilaku agar individu menjadi lebih adaptif (Jungquist et al., 2010).

Beberapa penelitian CBT telah terbukti efektif untuk menangani gejala pada pasien insomnia meskipun tidak disertai dengan pemberian obat atau terapi farmakologi (Williams, Roth, Vatthauer \& McCrae, 2013; Walia \& Mehra, 2016; Kryger, Roth \& Dement, 2017). Penelitian metanalisis yang dilakukan oleh Trauer, Qian, Doyle, Rajaratnam dan Cunnington (2015) menyatakan bahwa perlu adanya penelitian lebih lanjut pada pemberian CBT sebagai metode terapi utama tanpa adanya pemberian obat antipsikotik atau obat sedatif. Pertimbangan ini perlu dilakukan untuk efek kesembuhan jangka panjang dan kepuasan pasien. Penemuan ini kontras dengan penelitian Mao et al. (2017) yang membandingkan peningkatan kualitas tidur pada penderita insomnia yang hanya diberi obat dan kelompok lainnya diberikan obat bersamaan dengan terapi CBT yang menghasilkan kelompok yang diberi obat bersamaan dengan terapi CBT mengalami peningkatan kualitas tidur yang lebih signifikan daripada kelompok lainnya yang hanya mengonsumsi obat. Oleh karenanya, berdasarkan uraian di atas, penelitian ini bertujuan menguji efektivitas dari teknik CBT tanpa disertai pemberian obat untuk mengatasi insomnia pada individu, terutama usia dewasa awal dengan pola hidup berisiko.

\section{METODE}

Penelitian ini menggunakan metode penelitian eksperimental dengan desain eksperimen one group pre-test post-test. Untuk mengontrol validitas penelitian, kegiatan intervensi dilakukan di lokasi yang sama dengan perlakukan yang sama pada tiap-tiap subjek sesuai dengan acuan modul intervensi yang telah dibuat. Ada beberapa hal yang tidak dapat dikontrol oleh penulis, seperti kondisi masing-masing tempat tinggal subjek, kamar tidur, hal-hal yang dialami subjek pada hari di mana tidak dilakukan intervensi, dan lain sebagainya.

Eksperimen atau intervensi dilakukan dalam rentang waktu kurang lebih 28 hari yang dibagi dalam 5 kali pertemuan dengan total 6 sesi $(5$ minggu dengan 1 kali tatap muka setiap minggu). Durasi waktu pertemuan yang diperlukan kelompok dan terapis setiap minggunya adalah 90-120 menit. Jumlah pertemuan ini sesuai dengan modul pelaksanaan CBT untuk insomnia yang disusun oleh Jungquist et al. (2010) yang menyatakan bahwa efek terapeutik terapi secara umum memerlukan waktu 4-8 minggu dengan satu kali pertemuan tatap muka setiap minggunya antara pasien dengan terapis. Sesuai dengan kesepakatan seluruh subjek, pertemuan dilakukan setiap hari Jumat pada pukul 10.00 WIB hingga selesai. Seluruh kegiatan intervensi dilakukan di Laboratorium Psikologi Fakultas Psikologi Universitas Airlangga Surabaya.

Pemilihan subjek dilakukan dengan metode purposive sampling dengan kriteria subjek usia dewasa awal berusia 18-25 tahun, mengalami gejala insomnia minimal satu bulan terakhir, berdomisili di Surabaya, dan memenuhi kriteria keparahan insomnia (minimal kategori subthreshold insomnia) berdasarkan skala Insomnia Severity Index (ISI). Proses penyaringan subjek dilakukan secara online 
dengan menyebar kuesioner skala ISI. Pengukuran ISI kemudian akan kembali dilakukan saat pertengahan intervensi (sesi III) dengan tujuan mengetahui sesi intervensi nantinya dapat dilanjutkan atau tidak. Apabila subjek mengalami peningkatan tingkat keparahan dibandingkan dengan hasil screening maka intervensi tidak dapat dilanjutkan pada subjek tersebut dan disarankan untuk beralih pada pengobatan medis.

Responden awalnya berjumlah 52 orang dan sebanyak 35 responden memenuhi kriteria calon subjek. Sebanyak 17 orang responden lainnya gugur karena tidak memenuhi kriteria usia (lebih dari 25 tahun) dan tidak berdomisili di Surabaya. Selanjutnya, peneliti menyeleksi kembali 35 responden tersebut dan mengeliminasi responden yang adalah temanteman peneliti untuk mengurangi bias dalam proses intervensi hingga akhirnya menyisakan 16 responden. Setelah dihubungi melalui telepon, sebanyak 11 responden menyatakan tidak dapat mengikuti kegiatan intervensi secara rutin setiap minggunya karena ada kegiatan lain yang harus dikerjakan sehingga tersisa 6 responden. Setelah dijelaskan secara lebih detail proses intervensi yang akan dijalani, 2 orang menyatakan tidak bersedia mendapatkan penanganan dari peneliti terkait insomnia yang dialami karena merasa apa yang ia alami tidak memerlukan penanganan dari psikolog. Pada akhirnya terpilihlah 4 orang yang menyatakan bersedia berkomitmen untuk rutin datang pada kegiatan intervensi dan memiliki jadwal yang tidak bentrok satu sama lain. Jumlah ini memenuhi kriteria pemberian CBT untuk insomnia secara kelompok yang mana CBT efektif diberikan dalam kelompok dengan jumlah anggota antara 3-7 orang untuk menghindari anggota kelompok yang kurang mendapatkan perhatian terapis apabila jumlah anggota terlalu banyak (Verbeek, Konings, Aldenkamp, Declerck \& Klip, 2006; Yamadera et al., 2013).

CBT adalah salah satu jenis terapi yang berfokus pada perubahan pola kognitif, emosi, dan perilaku yang bersifat direktif, dibatasi oleh waktu, dan terstruktur untuk menangani berbagai gangguan mental (Fenn \& Byrne, 2013). Intervensi CBT yang diterapkan pada penelitian ini mengacu pada modul CBT untuk insomnia yang disusun oleh Jungquist et al. (2010). Modul ini disusun berdasarkan teori etiologi insomnia milik Spielman, yaitu ThreeFactors Model atau 3P Model. Menurut Spielman, etiologi insomnia dibagi menjadi 3 , yaitu: predisposing, precipitating, dan perpetuating (Spielman, Saskin \& Thorpy, 1987). Pelaksanaan terapi CBT untuk insomnia sendiri meliputi lima komponen sebagai berikut: Stimulus Control Therapy (SCT), Sleep Restriction Therapy (SRT), sleep hygiene education, cognitive therapy, dan relaxation training.

Untuk mengetahui perubahan kualitas tidur sebelum dan setelah diberikan intervensi CBT, peneliti menggunakan skala Pittsburgh Sleep Quality Index (PSQI) (Chronbach's Alpha $=0,83$ ) yang dikembangkan oleh Buysse, Reynolds, Monk, Berman dan Kupfer (1989). Skala ini terdiri dari 19 pertanyaan dengan rentang nilai 0-3 untuk masing-masing jawaban (tidak ada dalam satu bulan terakhir, kurang dari satu minggu sekali, satu atau dua kali dalam seminggu, dan tiga kali atau lebih dalam seminggu). Alat ukur ini dapat memberikan gambaran kualitas tidur individu selama satu bulan terakhir. Alat ukur ini dibagi menjadi 7 komponen, yaitu kualitas tidur subjektif, latensi tidur, durasi tidur, efisiensi kebiasaan tidur, gangguan saat tidur, penggunaan obat tidur, dan disfungsi pada siang hari.

Selain PSQI, pengukuran data juga dilakukan melalui penugasan rumah seperti sleep diary yang juga diberikan setiap minggunya sebagai data tambahan untuk mengukur Sleep Efficiency (SE) yang merupakan salah satu indikator dari kualitas tidur. Sleep diary adalah salah satu metode pengukuran tambahan yang umum digunakan dalam metode intervensi CBT untuk insomnia yang berisi beberapa indikator tertentu yang berkaitan dengan tidur (Davidson, Dawson \& Krsmanovic, 2017). Dalam sleep diary, terdapat tujuh kolom hari yang harus diisi sehingga di akhir pertemuan (sesi VI) dapat diperoleh perhitungan SE masing-masing subjek selama 28 hari. Hasil yang diperoleh dari sleep diary digunakan sebagai data analisa secara kuantitatif dan kualitatif.

Data skor PSQI yang diperoleh kemudian dianalisis menggunakan teknik statistik Wilcoxon Signed-Rank Tests (sig.< 0,05) karena teknik sampling yang digunakan bukanlah acak sehingga data tidak dapat dianalisis dengan teknik statistik parametrik. Data tersebut diolah dengan bantuan software SPSS. Hasil statistik yang diperoleh kemudian digunakan untuk menghitung effect size sehingga dapat diketahui tingkat efektivitas CBT terhadap peningkatan kualitas tidur keempat subjek. 


\section{HASIL}

\section{Karakteristik Subjek Penelitian}

Hasil penelitian menunjukkan rata-rata usia responden adalah 22,5 tahun yang seluruhnya berjenis kelamin perempuan (100,0\%). Pekerjaan yang dimiliki terdiri dari mahasiswa $(50,0 \%)$, karyawan $(25,0 \%)$, dan belum bekerja $(25,0 \%)$. Pendidikan terakhir adalah SMA $(50,0 \%)$ dan S1 $(50,0 \%)$.

\section{Hasil Masing-Masing Subjek}

Subjek Pertama. Subjek mengalami gejala insomnia sejak satu bulan terakhir. Subjek merasa cemas ketika waktu tidur tiba karena setiap ia memejamkan mata subjek mengaku melihat sosok malaikat maut yang akan mencabut nyawanya. Selain itu, subjek juga sering terbangun di malam hari. Subjek mengaku hanya mengalami ini ketika ia berada di kamarnya. Kesulitan tidur yang dialami subjek berakibat pada aktivitas kesehariannya yang mana ia merasa lelah dan tidak dapat berkonsentrasi sepanjang hari. Setelah mengikuti terapi CBT untuk insomnia selama 28 hari, subjek mengaku kualitas tidurnya lebih baik yang ditunjukkan dengan frekuensi terbangun saat tengah malam berkurang, jam tidur kembali teratur, tidak lagi cemas saat waktu tidur tiba, dan merasa lebih segar saat bangun pagi. Selama menjalani proses terapi, subjek kooperatif mengikuti seluruh rangkaian kegiatan yang menunjukkan bahwa subjek memiliki motivasi tinggi untuk mencapai kesembuhan. Selain itu, dukungan dari orang tua yang bersedia menemani subjek tidur saat subjek merasa ketakutan dan juga dukungan dari sesama subjek dalam terapi kelompok diakui sebagai salah satu faktor yang membantu penyembuhan. Subjek berhasil menghilangkan pikiran bahwa dirinya akan mati (melihat malaikat maut) setiap menjelang tidur melalui terapi kognitif pada salah satu sesi CBT. Subjek juga mengganti kebiasaan tidurnya dengan mematikan lampu kamar yang berakibat pada inisiasi waktu tidur yang lebih pendek. Kondisi ini menunjukkan bahwa faktor lingkungan (kondisi kamar tidur) juga berpengaruh pada peningkatkan kualitas tidur.

Subjek Kedua. Subjek mengalami gejala insomnia sejak tiga bulan terakhir. Subjek memiliki kegiatan yang cukup padat sehingga kondisi fisiknya menurun. Kondisi ini diperparah dengan penyakit asma yang dimiliki subjek yang sering kambuh saat malam hari ketika ia tidur. Setelah membaca beberapa artikel internet, subjek menemukan bahwa asma yang kambuh di malam hari memiliki risiko kematian yang lebih tinggi. Subjek mulai merasa gelisah saat hendak tidur dan terbangun berulang kali setelah berhasil tertidur. Setelah mendapatkan terapi CBT, subjek mengaku lebih mampu mengendalikan pikiran negatifnya yang disadari tidak masuk akal. Proses terapi yang dilakukan secara berkelompok diakui sangat membantu dalam proses perbaikan kualitas tidur. Selain dapat mendengarkan pengalaman subjek lain, subjek juga mendapatkan wadah yang tepat untuk berbagi gejala insomnia yang dialami karena selama ini subjek berusaha menyembunyikan kondisinya dari teman-temannya. Subjek juga mengaku jadwal tidurnya lebih teratur dengan menerapkan jadwal yang diberikan pada sesi terapi. Subjek menyadari bahwa kondisi kamar tidurnya yang berdebu dan berantakan menjadi salah satu alasan tidurnya tidak nyaman sehingga ia berupaya membuat kamarnya lebih bersih dan rapi. Selain berdampak pada kualitas tidur, kebersihan kamar juga diakui berdampak pada kondisi kesehatan subjek.

Subjek Ketiga. Subjek menderita insomnia sejak ayahnya meninggal dua tahun lalu. Hubungan subjek dan ayahnya tidak pernah baik sejak subjek kecil. Setelah ayahnya meninggal, subjek selalu bermimpi buruk tentang ayahnya sehingga membuat subjek selalu terbangun beberapa kali tengah malam dan tidak dapat kembali tidur. Waktu tidur yang subjek dapatkan setiap harinya hanya 3-4 jam sehingga berdampak pada kondisi fisiknya. Subjek merasa sakit kepala, kaku pada bagian leher, dan kelelahan sepanjang hari. Setelah menjalani terapi CBT, perubahan yang paling terasa adalah subjek dapat lebih memaafkan ayahnya setelah dapat mengubah distorsi kognitifnya dalam sesi intervensi. Subjek juga mendapatkan solusi atas masalah jam tidur dan keadaan lingkungan tempat tidurnya yang selama ini memperparah kondisi insomnianya. Subjek sering lupa mematikan lampu kamar dan mengecilkan volume kipas angin yang berdampak pada kondisi tidak segar saat bangun pagi.

Tabel 1 Data nilai perbandingan pengukuran

\begin{tabular}{ccccc}
\hline & $\begin{array}{c}\text { Pre-test } \\
\text { Mean } \\
\text { (SD) }\end{array}$ & $\begin{array}{c}\text { Min- } \\
\text { Max }\end{array}$ & $\begin{array}{c}\text { Post-test } \\
\text { Mean (SD) }\end{array}$ & $\begin{array}{c}\text { Min- } \\
\text { Max }\end{array}$ \\
\hline ISI & 19,6 & $17-22$ & 16,6 & $15-18$ \\
& $(2,1)$ & & $(1,5)$ & \\
PSQI & 13,5 & $10-16$ & 8 & $7-9$ \\
& $(2,5)$ & & $(0,8)$ & \\
Sleep & 73,3 & $67,9-$ & 83,4 & $81-$ \\
Efficiency & $(3,7)$ & 75,7 & $(3,3)$ & 87,9 \\
$(\%)$ & & & & \\
\hline
\end{tabular}


Tabel 2 Wilcoxon Signed-Rank test

\begin{tabular}{cc}
\hline \multicolumn{2}{c}{ Pre-test dan Post-test (PSQI) } \\
\hline Z & $-1,841^{\mathrm{b}}$ \\
Asymp. Sig. (2-tailed) & 0,036 \\
$\mathrm{~N}$ & 4 \\
\hline
\end{tabular}

Efek terapeutik juga dirasakan pada terapi CBT kelompok ini karena subjek merasa senang dapat membantu dan mendengarkan pengalaman orang lain dengan keluhan yang sama.

Subjek Keempat. Subjek mengalami gejala insomnia sejak satu tahun terakhir karena terbawa kebiasaannya saat kuliah di mana ia baru akan tidur jam 2 pagi karena mengerjakan tugas kuliah. Waktu tidur yang kurang ini mengakibatkan subjek mengantuk sepanjang hari dan kurang konsentrasi saat bekerja. Meskipun sudah mencoba membaca atau menonton televisi, namun cara tersebut tidak berhasil membuat subjek merasa mengantuk lebih cepat. Perubahan yang dialami subjek setelah menjalani intervensi CBT adalah pengetahuan akan jadwal dan ritme tidur yang juga berpengaruh pada ritme tubuh. Setelah mengetahui informasi tersebut, subjek mencoba menerapkan jadwal tidur yang sesuai dan memaksa dirinya untuk mematuhi anjuran selama proses intervensi. Subjek mencoba melakukan aktivitas yang membuatnya lelah sebelum tidur, seperti mencuci pakaian, merapikan kamar tidur, dan membersihkan kamar tidur. Cara tersebut berhasil membuatnya merasa lelah dan mempersingkat inisiasi waktu tidur. Kondisi kamar yang lebih bersih dan rapi membuat subjek lebih nyaman. Selain itu, subjek juga mengubah kebiasaannya yang selalu membiarkan televisi menyala sepanjang malam dengan volume yang terbilang mengganggu dan berakibat pada kualitas tidur yang kurang baik. Subjek menyadari bahwa cahaya televisi dan volume suaranya merupakan kondisi yang memengaruhi keparahan gejala insomnia yang ia alami selama ini.

\section{Nilai Perbandingan Pengukuran Pre dan Post-Test}

Tabel 3 Perhitungan effect size

\begin{tabular}{lc}
\hline \multicolumn{1}{c}{ Nilai } & Pre-test dan Post-test \\
\hline$Z$ & $-1,841$ \\
Jumlah kasus (subjek) & 4 \\
$\mathrm{~N}$ (jumlah kasus $\times 2$ ) & 8 \\
Nilai $r$ & 0,651 \\
Keterangan & large effect \\
\hline
\end{tabular}

Tabel 1 memperlihatkan data perbandingan nilai rata-rata pengukuran pre-test dan posttest ISI, PSQI, dan sleep efficiency. Pada alat ukur ISI dan PSQI terjadi penurunan rata-rata dari sebelum ke sesudah diberikan CBT yang menunjukkan adanya peningkatan kualitas tidur subjek. Pada aspek sleep efficiency terjadi peningkatan persentase sebelum dan sesudah intervensi yang juga mengindikasikan adanya peningkatan kualitas tidur subjek.

\section{Pittsburgh Sleep Quality Index}

Berdasarkan Tabel 2, nilai signifikansi (2tailed) uji Wilcoxon Signed-Rank Test adalah 0,036 . Jika nilai signifikansi lebih kecil dari 0,05 (sig. < 0,05) maka Ho ditolak dan apabila lebih besar dari 0,05 maka Ho diterima. Hal ini berarti bahwa pemberian intervensi Cognitive Behavior Therapy (CBT) efektif untuk meningkatkan kualitas tidur penderita gejala insomnia usia dewasa awal.

Selanjutnya, pada Tabel 3 dapat diketahui besaran effect size ( $r$ ) dari terapi CBT yang dilakukan terhadap kelompok subjek. Hasil penelitian menunjukkan bahwa semakin nilai $r$ mendekati 1 maka menunjukkan efek terapi yang semakin besar pada kelompok subjek. Hal tersebut didasarkan pada penilaian bahwa jika nilai $r$ adalah antara 0,1 hingga 0,3 maka tergolong pada small effect; jika nilai $r$ antara 0,3 hingga 0,5 tergolong pada medium effect; dan jika nilai $r>0,5$ maka tergolong large effect (Maher, Markey, \& Ebert-May, 2013).

\section{Sleep Diary}

Perhitungan sleep diary yang telah diisi oleh masing-masing subjek selama 28 hari pelaksanaan intervensi menghasilkan nilai sleep efficiency (SE). Dinamika SE dari keempat subjek dapat dilihat pada Gambar 1 yang mana subjek 1 dan 2 lebih konstan dibandingkan subjek 3 dan 4 . Peningkatan persentase SE yang menunjukkan kualitas tidur baik $(>90,0 \%)$ baru ditunjukkan memasuki intervensi pada minggu ke-3 yang diperoleh subjek 2 dan 4.

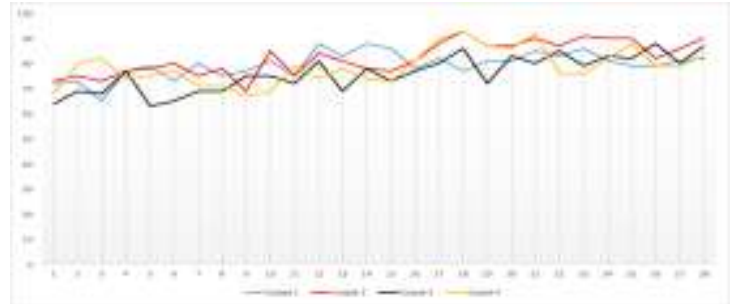

Gambar 1 Persentase sleep efficiency 


\section{PEMBAHASAN}

Hasil penelitian ini menunjukkan bahwa Cognitive Behavior Therapy (CBT) efektif untuk meningkatkan kualitas tidur pada penderita insomnia usia dewasa awal. Hal ini dibuktikan dengan penurunan tingkat keparahan subjek dari skor pre-test ke posttest dengan alat ukur ISI dan PSQI (Tabel 1). Kondisi ini dapat terjadi dikarenakan adanya faktor internal (motivasi dan kepatuhan) dan eksternal (dukungan dan petunjuk terapi yang tepat). Hasil ini didukung oleh penelitian sebelumnya yang dilakukan oleh Asano et al. (2015) yang menyatakan bahwa faktor internal pasien insomnia seperti motivasi yang tinggi akan menimbulkan perilaku determinasi tinggi yang akan membuat pasien patuh pada tahapan intervensi. Penelitian Taylor \& Puriksma (2014) menyebutkan bahwa adanya terapis atau ahli yang memandu pasien insomnia untuk melakukan serangkaian tahapan intervensi CBT dapat meningkatkan tingkat keberhasilan terapi tersebut. Faktor eksternal lain yaitu dukungan diperoleh dari sesama subjek dalam kelompok penelitian ini. Subjek dapat berbagi pengalaman, pendapat, dan masukan satu sama lain sehingga subjek merasa terbantu. Hal ini sesuai dengan penelitian Davidson, Dawson dan Krsmanovic (2017) yang menyatakan bahwa salah satu keuntungan terapi CBT untuk insomnia yang dilakukan berkelompok adalah dukungan yang diberikan antarsesama pasien sehingga merasa dipahami dan mengurangi perasaan tertekan dengan saling berbagi satu sama lain.

Pelaksanaan intervensi CBT dapat dilakukan secara berkelompok maupun individual. Pada penelitian ini, intervensi dilakukan secara berkelompok dengan tujuan untuk mempermudah dalam mengontrol variabel dan anggota kelompok intervensi memperoleh efek terapeutik dari proses intervensi kelompok. Selama proses intervensi berlangsung, subjek saling menanggapi keluhan dan cerita yang disampaikan satu sama lain terkait gejala insomnia yang dialami. Hal ini membuat subjek menjadi lebih mudah belajar dari pengalaman satu sama lain dan kemudian dapat diterapkan pada dirinya. Temuan ini sejalan dengan penelitian sebelumnya oleh Verbeek, Konings, Aldenkamp, Declerck dan Klip (2006) yang menyatakan bahwa pelaksanaan CBT kelompok untuk insomnia memiliki dua keuntungan, yaitu memberi kesempatan partisipan untuk bertemu pasien lain dengan keluhan yang sama dan lebih hemat secara biaya.
Seperti yang telah disebutkan pada bagian metode bahwa terapi CBT untuk insomnia terdiri dari 5 komponen, yaitu stimulus control therapy (SCT), sleep restriction therapy (SRT), sleep hygiene education, cognitive therapy, dan relaxation training. Dari kelima komponen tersebut, komponen SCT dan SRT adalah yang paling efektif untuk meningkatkan kualitas tidur. Temuan ini dibuktikan dengan dengan hasil wawancara pada keempat subjek yang mencoba untuk menerapkan aturanaturan tidur yang diperoleh dari sesi SCT dan SRT (sesi II) hingga pertemuan sesi IV karena metode penjadwalan waktu tidur-bangun dianggap dapat memperbaiki waktu tidur yang tidak teratur. Selain itu, metode penjadwalan ini juga dapat membantu tubuh untuk terbiasa dengan ritme tidur yang baru. Pada penelitian ini setelah sesi intervensi berakhir, beberapa subjek mengaku masih berusaha menetapkan waktu tidur dan bangun yang lebih teratur agar terpola dengan baik dalam keseharian mereka. Subjek juga menerapkan peraturan seperti menghindari terlalu banyak mengobrol, bertelepon, menggunakan internet, dan berpikir terlalu keras di atas tempat tidur dengan memfokuskan pada pengertian tempat tidur adalah tempat untuk istirahat atau tidur. Kegiatan lain selain tidur sebisa mungkin tidak dilakukan di atas tempat tidur. Hasil ini sesuai dengan penelitian Koffel, Koffel dan Gehrman (2015); Maoet al. (2017); Schlarb, Faber dan Hautzinger (2018) yang juga menyatakan bahwa komponen SCT dan SRT lebih efektif memberikan pengaruh positif pada kualitas tidur dibandingkan sleep hygiene yang tidak menunjukkan pengaruh pada kualitas tidur subjek. Hal ini disebabkan oleh komponen tersebut menyediakan peraturan yang bersifat jelas dan kaku sehingga pasien lebih mudah menerapkan aturan tersebut.

Hasil pengukuran pre-test dan post-test dengan menggunakan skala PSQI berdasarkan kategorisasi yang dinyatakan oleh Lund, Reider, Whiting, dan Prichard (2010) menunjukkan adanya peningkatan kualitas tidur meskipun tiga subjek masih termasuk dalam kategori buruk dan satu subjek termasuk dalam kategori borderline. Perolehan gain score keempat subjek belum dapat membedakan kualitas tidur yang baik dan buruk berdasarkan kategorisasi skala PSQI meskipun secara subjektif responden sudah merasakan adanya perubahan kualitas tidur yang lebih baik dan mengalami penurunan skor yang menunjukkan kualitas tidur yang lebih baik pada skala PSQI. Meskipun demikian, adanya penurunan skor pada skala PSQI dapat tetap dinyatakan sebagai 
peningkatan kualitas tidur sekalipun perolehan skor masih berada pada kategori buruk. Pernyataan ini didukung oleh penelitian CBT untuk pasien insomnia kronis yang dilakukan oleh Yi et al. (2012) yang tidak melakukan kategorisasi pada hasil PSQI yang diperoleh pada lima orang pasiennya karena dianggap telah mengalami peningkatan kualitas tidur apabila terjadi penurunan skor global skala PSQI dan Beck Depression Inventory (BDI).

Selain itu, terjadinya perubahan kualitas tidur pada pasien insomnia memerlukan waktu pelaksanaan intervensi yang tidak sebentar. Dalam penelitian ini hanya melakukan intervensi CBT selama kurang lebih lima minggu dengan jadwal satu kali pertemuan setiap minggunya sehingga secara kualitas masih belum memenuhi standar terapi klinis yang biasanya dilakukan dalam setting medis. Perlu jangka waktu terapi yang lebih lama dan disertai dengan konseling individual bagi penderita insomnia untuk dapat memperoleh kualitas tidur yang benar-benar membaik. Keterbatasan ini berkaitan dengan setting penelitian eksperimen ini yang mana perlakuan yang diberikan harus terkontrol dan sama bagi setiap subjek penelitian sehingga mengakibatkan konseling individual tidak dapat dilaksanakan. Selain itu, keterbatasan waktu masing-masing subjek untuk dapat mengikuti jadwal pertemuan juga merupakan salah satu penyebab intervensi tidak dilakukan lebih dari lima minggu. Menurut Takano et al. (2016) intervensi CBT sebaiknya dilakukan dalam jangka waktu kurang lebih 2 bulan dengan konseling individual pada sesi awal dan akhir.

Hasil penelitian menunjukkan terjadi peningkatan kualitas tidur penelitian meskipun secara statistik angka tersebut tidak terlalu signifikan. Adanya perubahan kualitas tidur diambil dengan lebih menitikberatkan pada evaluasi subjektif masing-masing responden dan peneliti selama proses intervensi berlangsung. Setelah proses intervensi CBT diakhiri, perlu dilakukan follow-up dalam jangka waktu tertentu sebagai upaya evaluasi pada kualitas tidur dan tingkat stres agar kondisi responden tidak kembali seperti sebelum menerima intervensi (Takano et al., 2016). Prevalensi insomnia berdasarkan jenis kelamin juga merupakan salah satu faktor yang dipertimbangkan oleh peneliti. Berdasarkan data prevalensi insomnia, disebutkan bahwa proporsi wanita lebih tinggi untuk mengalami insomnia $(44,6 \%)$ daripada proporsi laki-laki $(30,1 \%)$ (Madrid-Valero, Martinez-Selva, Couto, Sanchez-Romera \& Ordonana, 2017). Hal ini disebabkan karena perbedaan faktor biologis, sosiodemografis, dan juga gaya hidup (Fatima, Doi, Najman, \& Al-Mamun, 2016).

Wanita usia dewasa muda memiliki siklus perubahan hormon yang lebih sering daripada pria. Misalnya perubahan hormon estrogen karena siklus menstruasi yang menyebabkan wanita rentan mengalami perubahan suasana hati dan mudah merasa stres. Hormon lain seperti peningkatan adrenalin secara tiba-tiba juga dapat membuat otak terbangun dan menyebabkan wanita berkeringat karena temperatur tubuh yang ikut meningkat. Kenaikan temperatur tubuh ini menyebabkan wanita mengalami tidur yang kurang nyaman sepanjang malam dibandingkan pria. Pada pria, faktor gaya hidup yang tidak sehat lebih berpengaruh pada kualitas tidur dibandingkan faktor hormon (Fatima, Doi, Najman \& AlMamun, 2016). Temuan ini juga sejalan dengan penelitian tentang insomnia yang dilakukan di China (Tang et al., 2017) dan Taiwan (Tsou, 2018). Hasil dari kedua penelitian tersebut menemukan adanya perbedaan signifikan pada kualitas tidur. Wanita memiliki kualitas tidur yang lebih buruk daripada pria. Faktor ini menjadi salah satu latar belakang penelitian ini seluruhnya mengambil contoh berjenis kelamin wanita.

Selain faktor internal dan eksternal yang telah disebutkan sebelumnya, penelitian ini juga menemukan bahwa faktor lingkungan dapat menjadi penyebab seseorang mengalami gangguan tidur, seperti suhu ruangan yang terlalu panas atau dingin, terlalu berisik, pencahayaan terlalu terang, dan adanya gangguan lingkungan sekitar yang terlalu berisik. Selain lingkungan, insomnia juga disebabkan oleh kondisi fisik yang memengaruhi kondisi psikologis individu. Seperti penyakit fisik bawaan yang dialami salah satu subjek (asma dan pembengkakan kelenjar getah bening) yang berakibat pada stres berkepanjangan. Adanya trauma pada kejadian masa lalu dan penerapan pola tidur yang salah juga menjadi faktor penyebab insomnia dalam penelitian ini. Temuan tersebut sesuai dengan pernyataan Tibbits (2008) bahwa insomnia dapat diakibatkan oleh kondisi psikis dan medis yang diperparah oleh tekanan, perubahan waktu tidur (jet lag atau shift kerja), dan faktor lingkungan yang kurang mendukung (suhu ruangan atau suara berisik).

Pada penelitian ini ditemukan bahwa dukungan keluarga adalah salah satu aspek yang memengaruhi peningkatan kualitas tidur pada subjek penderita insomnia. Dari hasil 
wawancara diperoleh pernyataan keempat subjek bahwa keluarga dan teman dekat merupakan sumber kekuatan utama sehingga mereka dapat bertahan sejak awal mengalami insomnia. Subjek 1 dan 2 yang tinggal satu rumah dengan orang tuanya merasakan kehangatan dari ibu yang akan memeluk dan menenangkan saat subjek menangis karena sulit tidur. Meskipun tidak secara langsung menyembuhkan insomnia, tetapi dukungan langsung dari ibunya diakui oleh subjek membantu menenangkan pikiran mereka. Subjek 4 mengaku ia sama sekali tidak mengalami insomnia ketika pulang ke rumah orang tuanya. la merasa tenang saat berada bersama keluarganya sehingga jam tidurnya kembali normal. Hal ini berbeda dengan subjek 3 yang sama sekali tidak mau keluarga dan teman-temannya mengetahui insomnia yang ia alami sehingga tidak memperoleh dukungan orang terdekat. Periode insomnia yang ia alami pun terbilang lebih lama (2 tahun) dibandingkan subjek lainnya yang rata-rata menderita insomnia sejak 6-12 bulan terakhir. Hasil ini sesuai dengan penelitian yang dilakukan oleh Abdullah, Yasin dan Yahya (2012) yang mengatakan bahwa keluarga dan teman dekat berperan untuk meyakinkan kembali dan mengurangi kekhawatiran akan rasa aman bagi penderita insomnia. Keluarga adalah tempat pertama penderita meminta pertolongan saat merasa tidak nyaman sehingga menjadikan keluarga adalah sumber motivasi paling utama. Waktu yang diluangkan oleh keluarga untuk berbincang dengan penderita dapat menjadi sumber motivasi untuk dapat mengurangi risiko depresi. Argumen ini juga didukung oleh penelitian Nakata et al. (2004) yang menyatakan bahwa seorang pekerja dengan dukungan keluarga yang rendah memiliki hubungan yang signifikan dengan risiko meningkatnya terbangun lebih cepat dari waktu yang seharusnya sehingga menurunkan kualitas tidur. Kehangatan yang diperoleh dari dukungan keluarga dapat membuat individu pekerja merasa lebih tenang sehingga kualitas tidur akan lebih baik.

Berdasarkan Teori etiologi insomnia, CBT untuk insomnia adalah metode intervensi nonfarmakologis yang tepat diterapkan untuk kasus insomnia, terutama untuk meningkatkan kualitas tidur. Modul penerapan CBT untuk insomnia yang disusun oleh Jungquist et al. (2010) menyediakan komponen atau sesi terapi yang dibutuhkan oleh para penderita insomnia, seperti: stimulus control therapy, sleep restriction therapy, dan sleep hygiene education. Komponen terapi tersebut memberikan kondisi dan aturan yang jelas untuk ditaati dan diterapkan oleh penderita insomnia yang berfokus langsung untuk mengurangi pola perilaku yang salah. Pergeseran pola kognitif (distorsi kognitif) juga dapat dikurangi melalui komponen cognitive therapy yang bertujuan untuk menggantikan belief yang lama dengan belief baru agar penderita memiliki pola pemikiran yang lebih sehat dan adaptif. Keterampilan relaksasi juga diberikan sebagai salah satu upaya untuk menurunkan rasa cemas, ketakutan, dan tekanan yang timbul pada diri penderita setiap menjelang waktu tidur karena adanya pikiran bahwa ia tidak akan dapat tertidur seperti malam-malam sebelumnya.

\section{SIMPULAN DAN SARAN}

Berdasarkan hasil penelitian yang telah dilakukan, diperoleh bahwa intervensi Cognitive Behavior Therapy (CBT) efektif secara signifikan untuk meningkatkan kualitas tidur penderita gejala insomnia usia dewasa awal. Nilai effect size yang diperoleh tergolong pada kategori large effect yang berarti intervensi CBT memberikan dampak yang besar bagi peningkatan kualitas tidur penderita gejala insomnia. Selain itu CBT dapat meningkatkan sleep efficiency pada masingmasing responden. Perubahan lainnya juga terjadi secara kognitif yang mana subjek telah mampu mengubah distorsi kognitif tentang tidur yang sebelumnya menjadi suatu kalimat pemikiran yang lebih positif dan rasional. Berdasarkan hasil evaluasi yang dilakukan pada keempat subjek, komponen CBT yang paling berpengaruh adalah stimulus control and sleep restriction.

Jumlah contoh yang kecil dan teknik sampling non-random pada penelitian ini membuat hasil tidak dapat digeneralisasikan pada populasi sehingga pada penelitian berikutnya diharapkan jumlah contoh yang digunakan lebih besar. Selain itu, perlu adanya pertimbangan kehadiran variabel lain di luar variabel eksperimen yang dapat memengaruhi keberhasilan dan hasil penelitian. Penelitian selanjutnya juga dapat mempertimbangkan adanya kelompok kontrol untuk memperkuat dasar uji hipotesis. Berdasarkan hasil, pasien insomnia sebaiknya segera mencari bantuan ahli sebelum gejala insomnia semakin parah. Hal ini dilakukan agar penanganan baik secara farmakologi maupun non farmakologi dapat dilakukan sesegera mungkin sesuai dengan anjuran ahli. Keluarga pasien diharapkan dapat memberikan dukungan dengan meluangkan waktu untuk berbincang atau 
berusaha menenangkan pasien insomnia agar mereka dapat merasa lebih tenang sehingga dapat meningkatkan kualitas tidur. Hal lain yang dapat dilakukan keluarga adalah menyediakan lingkungan tidur yang lebih kondusif (pencahayaan, kebisingan, dan kebersihan kamar tidur) dan membantu mengingatkan pasien untuk tidak mengonsumsi atau melakukan aktivitas sebelum tidur yang dapat memperparah kondisi insomnia.

\section{DAFTAR PUSTAKA}

Abdullah, A.Z., Arsin, A.A., \& Yahya, M. (2012). Determinan insomnia pada lanjut usia. Jurnal Kesehatan Masyarakat Nasional, 7, (4), 154-157. doi: 10.21109/kesmas.v7i4.51.

American Psychiatric Association. (2013). Diagnostic and Statistical Manual of Mental Disorders (Fifth Edition). Washington, DC: American Psychiatric Association.

American Psychological Association. (2017). Stress in America: The State of Our Nation. Diaskes pada tanggal 19 September 2018 dari https://www.apa.org/news/press/releases/ stress/2017/state-nation.pdf

Asano, K., Ishimura, I., Abe, H., Nakazato, M., Nakagawa, A., \& Shimizu, E. (2015). Cognitive behavioral therapy as the basis for preventive intervention in a sleep health program: aquasi-experimental study of e-Mail newsletters to college students. Open Journal of Medical Psychology, 4, 9-16, doi: 10.4236/ojmp.2015.41002.

Aulia, S., \& Panjaitan, R.U. (2019). Kesejahteraan psikologis dan tingkat stres pada mahasiswa tingkat akhir. Jurnal Keperawatan Jiwa, 7, (2), 127-134

Buysse, D.J., Reynolds,C.F., Monk,T.H., Berman,S.R., \& Kupfer,D.J. (1989). The Pittsburgh Sleep Quality Index (PSQI): a new instrument for psychiatric research and practice. Psychiatry Research, 28(2), 193-213, 1989, doi: 10.5665/sleep.3298.

Chamberlain, S.R. \& Grant, J.E. (2019). Relationship between quality of life in young adults and impulsivity/compulsivity. Psychiatry Research (271), 253-258, doi: 10.1016/j.psychres.2018.11.059.

Chan, V., Moore, J., Derenne, J., \& Fuchs, D.C. (2019). Transitional age youth and college mental health. Child Adolescence
Psychiatric Clininal N Am, 363-375, doi: https://doi.org/10.1016/j.chc.2019.02.008.

Cunnington, D., Junge, M.F., \& Fernando, A.T. (2013). Insomnia: prevalence, consequences and effective treatment. MJA, 199: S36-S40, doi: 10.5694/mja13.10718.

Davidson, J.R., Dawson, S., \& Krsmanovic, A. (2017). Effectiveness of group Cognitive Behavioral Therapy for Insomnia (CBT-I) in a primary care setting. Behavioral Sleep Medicine, 00:1-13, doi: 10.1080/15402002.2017.1318753

Driver, H., Gottschalk, R., Hussain, M., Morin, C.M., Shapiro, C., \& Zyl, L.V. (2012). Insomnia in Adults and Children. Ontario, Canada: Joli Joco Publications Inc

Fatima, Y., Doi, S.A.R., Najman, J., \& AlMamun, A. (2016). Exploring gender difference in sleep quality of young adults: findings from a large population study.Clinical Medicine \& Research 14, (3-4): 138-144, doi:10.3121/cmr.2016.1338.

Feldman, R.S. (2018). Development Across the Life Span: Eight Edition. England: Pearson Education Limited.

Fenn, M.K. \& Byrne. M. (2013). The key principles of cognitive behavioral therapy. InnovAiT, 6(9), 579-585, doi: 10.1177/1755738012471029.

Giri, P.A., Baviskar, M.P., \& Phalke, D.B. (2013). Study of sleep habits and sleep problems among medical students of Pravara Institute of Medical Sciences Loni, Western Maharashtra, India. Annals of Medical and Health Sciences Research, 2013, 3(1): 193-197, doi: 10.4103/2141-9248.109488.

Gunanthi, N.M.W.M. \& Diniari, N.K.S. (2016). Prevalensi dan gambaran gangguan tidur berdasarkan karakteristik mahasiswa Semester I Program Studi Pendidikan Dokter Fakultas Kedokteran Universitas Udayana Tahun 2015. E-Journal Medika, 5(4)

Hurlock, E.B. (2011). Psikologi Perkembangan: Suatu Pendekatan Sepanjang Rentang Kehidupan. Jakarta: Erlangga.

Hombali, A., Seow, E., Yuan, Q., Chang, S.H., Satghare, P., Kumar, S., Verma, S.K., Mok, Y.M., Chong, S.A., \& Subramaniam, M. (2018). Prevalence and correlates of sleep disorder symptomps in psychiatric disorders. Psychiatry Research, 2018 Jul 
6. pii: S0165-1781(18)30268-3, doi: 10.1016/j.psychres.2018.07.009.

Jungquist, C.R., O'Brien, C., Matteson-Rusby, S., Smith, M.T., Pigeon, W.R., Xia, Y., . . . Perlis, M.L. (2010). The efficacy of cognitive-behavioral therapy for insomnia in patients with chronic pain. Sleep Medicine 11(3), p.302-309, doi: 10.1016/j.sleep.2009.05.018.

Kryger, M., Roth, T., \& Dement, W.C. (2017). Principles and Practice of Sleep Medicine: Sixth Edition. Philadephia: Elsevier.

Koffel, E.A., Koffel, J.B., \& Gehrman, P.R. (2015). A Meta-analysis of group Cognitive Behavioral Therapy for insomnia. Sleep Medicine Reviews, 19,616. doi: 10.1016/j.sm rv.2014.05.001

Lee, J.O., Hill, K.G., Hartigan, L.A., Boden, J.M., Guttmannova, K., Kosterman, R., . . . Catalano, R.F. (2015). Unemployment and substance use problems among young adults: does childhood low socioeconomic status exacerbate the effect?. Social Science \& Medicine (143), 36-44,

doi: 10.1016/j.socscimed.2015.08.016.

Liu, J., Modrek, S., \& Sieverding, M. (2017). The mental health of youth adults during the transition to adulthood in Egypt. Demographic Research, 36, (56), 17211758, doi : 10.4054/DemRes.2017.36.56.

Lund, H.G., Reider, B.D., Whiting, A.B., \& Prichard, J.R. (2010). Sleep patterns and predictors of disturbed sleep in a large population of college students. Journal of Adolescent Health 46 (2010) 124-132, doi: 10.1016.j.jadohealth.2009.06.016.

Madrid-Valero, J.J., Martinez-Selva, J.M., Couto, B.R., Sanchez-Romera, J.F., \& Ordonana, J.R. (2017). Age and gender effects on the prevalence of poor sleep quality in the adult population.Gac Sanit, 2017:31(1) : 18-22, doi: 10.1016/j.gaceta.2016.05.013

Maher, J.M., Markey, J.C., \& Ebert-May, D. (2013). The other half of the story: effect size analysis in quantitative research. CBE-Life Sciences Education Vol.12, 345351, doi : $10.1187 / \mathrm{cbe} .13-04-0082$

Manber, R., Bernert, R.A., Suh, S., Nowakowski, S., Siebern, A.T., \& Ong, J.C. (2011). CBT for insomnia in patients with high and low depressive symptom severity: adherence and clinical outcomes. Journal of Clinical Sleep
Medicine, 7, (6), 645-652, doi: http://dx.doi.org/10.5664/jcsm.1472.

Manjavong, M., Limpawattana, P., Mairiang, P., \& Anutrakulchai, S. (2016). Prevalence of insomnia and related impact: an analysis from a university community. The Internasional Journal of Psychiatry in Medicine, 51(6) 544-553, doi: $10.1177 / 0091217417696731$.

Mao, H., Ji, Y., Xu, Y.,Tang, G., Yu, Z., Xu, L., ...Wang, W. (2017). Group-CognitiveBehavioral Therapy in insomnia: a crosssectional case-controleed study. Neuropsychiatric Disease and Treatment,13 : 2841-2848, doi: 10.2147/NDT.S149610

McMain, S., Newman, M.G., Segal, Z.V., \& DeRubeis, R,J. (2015). Cognitive bavioral therapy: current status and future research directions. Psychotherapy Research. 25(3),.321-329, doi: 10.1080/10503307.2014.1002440.

Morawetz, D. (2003). Insomnia and depression: which comes first?. Sleep Research Online 5(2): 77-81, 2003.

Nakata, A., Haratani, T., Takahashi, M., Kawakami, N., Arito, H., Kobayashi, F., \& Araki, S. (2004). Job stressm social support, and prevalence of insomnia in a population of Japanese daytime workers. Social Science \& Medicine 59, (2004), 1719-1730.

doi: 10.016/j.socscimed.2004.02.002.

Nurdin, M.A., Arsin, A.A., \& Thaha, R.M. (2018). Kualitas hidup penderita insomnia pada mahasiswa. Jurnal MKMI, 14 (2), doi: $10.30597 / \mathrm{mkmi} . v 14 i 1.3464$.

Robinson, O.C., \& Wright, G.R.T. (2013). The prevalence, types and percieved outcomes of crisis episodes in early adulthood and midlife: a structured retrospective-autobiographical study. Internasional Journal of Behavioral Development 37 (5): 407-416.

Sarmento, M. (2015). A mental health profile of higher education students. Social and Behavioral Sciences, 191:12-20, doi: 10.1016/j.sbspro.2015.04.606.

Schlarb, A.A., Faber, J., Hautzinger, M. (2018). CBT-I and HT-I Group Therapy for adults with insomnia in comparison to those with insomnia and comorbid depression-a pilot study. Neuopsychiatric Disease and Treatment, 14,2429-2438, doi: 10.2147/NDT.S164899. 
Spence, S.H. (2003). Social skills training with children and young people: theory, evidence, and practice. Child and Adolescent Mental Health,8, (2), 84-96.

Spielman, A.J., Saskin, P., Thorpy, M.J. (1987). Treatment of chronic insomnia by restriction of time in bed. Sleep, 10(1):4556 .

Takano, T., Isojima, M., Tanaka, M., Yamamoto, M., Sasaki, N., Somemura, H., Nakamura, S., Katsuragawa, S., \& Tanaka, K. (2016). Effects of brief CBT-I on sleep quality and psychological distress in shift workers without the midnight shift. Kitasato Medical Journal; 46: 118-125.

Tang, J., Liao, Y., Kelly, B.C., Xie, L., Xiang, Y.T., Qi, C., . . . Pan, C. (2017). Gender and regional differences in sleep quality and insomnia: a general population-based study in Hunan Province of China. Scientific Reports, 7:43690. doi: 10.1038/srep43690

Taylor, D.J., Gardner, C.E., Bramoweth, A.D., Williams, J.M., Roane, B.M., Grieser, E.A., \& Tatum, J.I. (2011). Insomnia and mental health in college students. Behavioral and Sleep Medicine, 9:107116, doi 10.1080/154002002.2011.557992.

Taylor, D.J. \& Pruiksma, K.E. (2014). Cognitive behavioural therapy for insomnia (CBT-I) in psychiatric populations: a systematic review. Internasional Review of Psychiatry, April 2014; 26 (2): 205-213, doi: 10.3109/09540261.2014.902808.

Taylor, D.J., Zimmerman, M.R., Gardner, C.E.,Williams, J.M., Grieser, E.A., Tatum, J.I., Bramoweth, A.D., Francetich, J.M., \& Ruggero, C. (2014). A pilot randomized controlled trial of the effects of CognitiveBehavioral Therapy for insomnia on sleep and daytime functioning in college students.Behavior Therapy, 45 (2014): 376-389.

Tibbits, G.M. (2008). Sleep disorders: causes, effects, and solutions. Primary Care: Clinics in Office Practice, 35(4),817-837, doi:10.1016/j.pop.2008.07.006.

Trauer, J.M., Qian, M.Y., Doyle, J.S., Rajaratnam, S.M.W., \& Cunnington, D. (2015). Cognitive behavioral therapy for chronic insomnia: a systematic review and meta-analysis. American College of
Physicians,
163:
191-204, doi:10.7326/M14-2841.

Tsou, M.T. (2018). Gender-specific correlations of insomnia and attitudes toward treatment among communitydwelling elderly in northern Taiwan. Internasional Journal of Gerontology 12 (2018) 200-204. doi: 10.1016/j.jjge.2017.07.002.

Verbeek, I.H., Konings, G.M., Aldenkamp, A.P., \& Declerck, A.C. (2006). Cognitive behavioral treatment in clinically referred chronic insomniacs: group versus individual treatment. Behavioral Sleep Medicine, 4(3), 135-151, doi: $10.1207 /$ s15402010bsm0403_1.

Walia, H.K., \& Mehra, R. (2016). Overview of common sleep disorders and intersection with dermatologic conditions. Internasional Journal of Molecular Sciences, $\quad 17,654$, doi:10.3390/ijms17050654.

Williams, J., Roth, A., Vatthauer, \& McCrae, C.S. (2013). Cognitive behavioral treatment of insomnia. Contemporary Reviews in Sleep Medicine, American College of Chest Physicians, doi: 10.1378/chest.12-0731.

World Health Organization. (2016). Work Organization \& Stress. Diakses pada tanggal 19 September 2018 dari http://www.who.int/occupational_health/pu blications/pwh3rev.pdf

Yamadera, W., Sato, M., Harada, D., Iwashita, M., Aoki, R., Obuchi, K., . . . Ozone, M. (2013). Comparisons of short-term efficacy between individual and group cognitive beavioral therapy for primary insomnia. Sleep and Biological Rhythms, 11: 176-184, doi:10.1111/sbr.12019.

Yi, M.J., Kim, T.W., Jeong, J.H., Joo, S.H., Hong, S.C., \& Suh, Soo Yeon. (2012). Case studies of chronic insomnia patients participating in group Cognitive Behavioral Therapy for Insomnia. Sleep Medication Research, 3:45-49, doi: 10.17241/smr.2012.3.2.45

Ypsilanti, A., Lazuras, L., Robson, A., \& Akram, U. (2018). Anxiety and depression mediate the relationship between selfdisgust and insomnia disorder. Journal of the National Sleep Foundation 4(4):349351, doi: 10.1016/j.sleh.2018.06.001. 